\title{
Inactivación Térmica de Pectinmetilesterasa en Tomate de Árbol (Solanum betaceum)
}

\author{
Maira P. Maca, Oswaldo Osorio y Diego F. Mejía-España* \\ Universidad de Nariño, Facultad de Ingeniería Agroindustrial, Ciudad Universitaria Torobajo - Calle $18 \mathrm{Cr}$ \\ 50, San Juan de Pasto - Colombia (e-mail: mairap88@hotmail.com; osorio_oswaldo@hotmail.com; \\ diegomejiaes@udenar.edu.co)
}

* Autor a quien debe ser dirigida la correspondencia

Recibido Nov. 22, 2012; Aceptado Ene. 08, 2013; Versión final recibida Mar. 05, 2013

\section{Resumen}

El objetivo de esta investigación fue estudiar el efecto del procesamiento térmico a temperatura constante, sobre la actividad residual de la enzima pectinmetilesterasa (PME), causante de la separación de fases en néctar de tomate de árbol (Solanum betaceum). Se evaluó un rango de temperaturas entre 40 y $90^{\circ} \mathrm{C}$ y tiempos de exposición entre los 5 y 20s. La actividad enzimática residual se midió por espectrofotometría a una longitud de onda de $620 \mathrm{~nm}$. Se determinó el contenido de proteína mediante el método de Bradford. El tratamiento térmico aplicado a $60^{\circ} \mathrm{C}$ durante 20 segundos de exposición redujo la actividad residual de PME hasta un $10 \%$ evitando la separación de fases del néctar. Se concluye que el tratamiento aplicado disminuyó el contenido de enzima en un $28 \%$ con respecto al testigo sin tratar.

Palabras clave: actividad residual, pectinmetilesterasa, tomate de árbol, tratamiento térmico, inactivación térmica

\section{Thermal Inactivation of Pectinmethylesterase in Tree Tomato (Solanum betaceum)}

\begin{abstract}
The effect of batch thermal processing on the residual activity of pectinmethylesterase enzyme (PME) in tree tomato (Solanum betaceum) was studied. Batch processes were conducted at temperatures between 40 and $90^{\circ} \mathrm{C}$ and exposure times from 5 to 20 s. Residual enzyme activity was spectrophotometrically measured at $620 \mathrm{~nm}$ wavelength. The protein content was determined according to Bradford's dye binding method. The thermal treatment applied to $60^{\circ} \mathrm{C}$ for 20 seconds exposure time, reduced the residual activity of PME to $10 \%$ avoiding phase separation. It is concluded that the thermal treatment applied caused a decrease on enzyme content to $28 \%$ from initial content.
\end{abstract}

Keywords: residual activity, pectinmethylesterase, tree tomato, heat treatment, thermal inactivation 


\section{INTRODUCCIÓN}

La PME (EC 3.1.1.11) es una enzima hidrolítica, que se encuentra de manera natural en la mayoría de las frutas, ligada a la pared celular y es liberada en el momento de la extracción del zumo (Polydera et al., 2004); cataliza la eliminación de los grupos metilo de la cadena de ácido poligalacturónico, lo que provoca la liberación de metanol, pectinas de bajo metoxilo y formación de ácidos pécticos (Menéndez Aguirre et al., 2006). Estos ácidos pueden reaccionar con iones calcio presentes en el medio para formar complejos insolubles de pectato de calcio, dejando un mayor número de grupos carboxilo libres que pueden luego enlazar cationes y formar pectinas reticuladas, las cuales pueden agregarse y asentarse (Anthon et al., 2002; de Assis et al., 2001).

Los jugos contienen finas partículas compuestas por pectina, celulosa, hemicelulosa, proteínas y lípidos en suspensión, lo cual se considera una característica deseable, ya que afecta favorablemente el sabor y el color característico en estos productos (Carbonell et al., 2005). La clarificación por acción enzimática se considera un defecto asociado con la pérdida de calidad de algunos jugos ricos en PME, como los de cítricos y tomate de mesa (Solanum lycopersicum), causando separación de fases, pérdida de turbidez, modificación de la textura, reducción en la viscosidad, pérdida de color y poca retención del sabor (Giner et al., 2000), al igual que en el jugo de tomate de árbol. Estos problemas se han atribuido principalmente a la actividad de la PME; por lo tanto, el control de su actividad es un importante punto de interés para obtener productos de alta aceptación por los consumidores (Jolie et al., 2009).

Investigaciones realizadas en frutas han establecido que un proceso muy efectivo para la inactivación de PME es la pasteurización (Polydera et al., 2004); este es un procedimiento relativamente suave, que contribuye con el aumento de la vida útil del alimento sobre el que se aplica, siempre que se mantenga posteriormente refrigerado o se complemente con otros métodos de conservación (Lewis y Heppell, 2000; Luíz et al., 2007). Actualmente, los consumidores buscan alimentos no sólo con larga vida útil sino también de alta calidad, con mínimas pérdidas en sus nutrientes y cualidades organolépticas; para satisfacer estas exigencias, los fabricantes han buscado mejorar los procesos de conservación por calor, como la pasteurización a altas temperaturas y tiempos cortos, los tratamientos a ultra alta temperatura (HTST y UHT, respectivamente, por sus siglas en inglés) y el envasado aséptico (Cruz et al., 2006; Jolie et al., 2009; Rivas et al., 2006)

Los jugos de fruta pasteurizados y refrigerados mantienen su calidad sensorial, nutritiva y funcional mejor que los zumos esterilizados y son preferidos por los consumidores a pesar de la necesidad de almacenamiento refrigerado y su corta vida comercial (Osorio et al., 2008). Se ha determinado que la temperatura de inactivación de PME es variada y depende del sustrato donde se encuentre. En el proceso de elaboración de sopas y jugos de tomate de mesa, el homogeneizado se calienta a temperaturas cercanas a los $60^{\circ} \mathrm{C}$; estos niveles retienen mejor los componentes de color y sabor y reducen la producción de compuestos indeseables. Aunque no se inactiva completamente las enzimas PME y Poligalacturonasa (PG), el proceso permite que estas enzimas descompongan algunas de las pectinas reduciendo la viscosidad del jugo, lo cual afecta favorablemente su bombeo y evaporación (Anthon et al., 2002).

Diversos autores coinciden en que el porcentaje de actividad residual (\%AR) de la enzima para zumos tratados térmicamente debe ser de un 10\%, para disminuir el riesgo de alterar las propiedades sensoriales, fisicoquímicas y nutritivas del producto (Carbonell et al., 2005; Ingallinera et al., 2005; Osorio et al., 2008; Sentandreu et al., 2005; Torres et al., 2008).

Si bien la PME ha sido estudiada en una gran cantidad de frutas no hay reportes de esta enzima en tomate de árbol. En otros jugos de frutas, como la naranja, se ha recomendado ajustar las condiciones de tratamiento térmico para reducir la actividad de PME (Giner et al., 2000). También se encuentran estudios en maracuyá (Vivar-Vera et al., 2007), fresa (Osorio et al., 2008) y frambuesa (Jakób et al., 2009) entre otras. El objetivo de esta investigación fue inactivar parcialmente la enzima PME, causante de la separación de fases en el zumo de tomate de árbol. Asimismo, se cuantificó la cantidad de enzima presente antes y después del tratamiento.

\section{MATERIALES Y MÉTODOS}

\section{Materia prima}

Los frutos de tomate de árbol (Solanum betaceum), fueron recolectados en 10 municipios del departamento de Nariño, Colombia y procesados en la Planta Piloto de la Universidad de Nariño. 


\section{Extracción de pulpa}

Los frutos se seleccionaron por su estado de sanidad, se pesaron y se clasificaron de acuerdo con su estado de madurez de consumo, escogiendo solo los frutos en escala 5 y 6 acorde con la norma NTC 4105 (ICONTEC, 1997). En seguida se lavaron y desinfectaron por inmersión en una solución de hipoclorito de sodio $(50 \mathrm{ppm})$ durante 5 minutos y se enjuagaron con agua potable. Posteriormente se escurrieron, pelaron y se sometieron a trituración en una licuadora industrial marca JAVAR LCT-15. La pulpa obtenida se filtró para retirar las semillas, luego se homogenizó y empacó en bolsas herméticas de polietileno con capacidad de $15 \mathrm{~mL}$, las cuales se conservaron congeladas a $-23^{\circ} \mathrm{C}$, con el fin de evitar variabilidad en los resultados.

\section{Extracción enzimática}

El extracto enzimático se preparó diariamente, siguiendo el protocolo propuesto por Vicente (2004). A $5 \mathrm{~g}$ de pulpa de tomate de árbol previamente descongelada, se agregaron $15 \mathrm{~mL}$ de solución de cloruro de sodio ( $\mathrm{NaCl}) 1 \mathrm{M}$ y $0,04 \mathrm{~g}$ de polivinilpirrolidona (PVPP). La suspensión obtenida se agitó por 1h a $200 \mathrm{rpm}$ a temperatura ambiente; el sobrenadante se centrifugó a $10.000 \mathrm{rpm}$ por 1 hora a $4^{\circ} \mathrm{C}$, en una centrífuga Thermo IEC Multi RF, refrigerada. El precipitado fue desechado y el sobrenadante se utilizó como extracto enzimático. Todos los reactivos utilizados fueron grado analítico.

\section{Tratamiento térmico}

Los tratamientos se hicieron utilizando la metodología desarrollada por Anthon y Barrett (2002): el extracto enzimático se envasó en tubos capilares de vidrio tipo microhematocrito (Longitud $75 \pm 1,5 \mathrm{~mm}$; diámetro interno 1,1-1,2 mm; diámetro externo 1,4 -1,6 mm; espesor de paredes 0,2 \pm 0,02 mm; capacidad volumétrica $75-80 \mu \mathrm{L}$ ). Esto permitió minimizar el tiempo de subida de la temperatura hasta que fue de 10 segundos y mejorar la transferencia de calor minimizando la degradación de los compuestos de interés (Fellows, 1994).

Los tubos capilares se colocaron en un baño de agua termostatado marca Eyela OSB 2000 con capacidad de 10 litros, y precisión de $0,1^{\circ} \mathrm{C}$. La temperatura se midió con un lector de temperatura portátil (TECPEL DTM-305), al cual se acopló un termopar tipo K.

Las muestras una vez calentadas por el tiempo especificado, se transfirieron inmediatamente a un baño de agua-hielo a temperatura de $2^{\circ} \mathrm{C}$ con el fin de someterlas a un brusco choque térmico (Thongsook y Barrett, 2005).

\section{Medida de la actividad enzimática}

La actividad enzimática se midió utilizando un espectrofotómetro Genesys 10 (Thermo Scientific) UV-VIS con escaneo de 6 celdas, aplicando la metodología reportada por Hagerman y Austin, (1986) y Giner et al., (2000). La mezcla de reacción contenía $95 \mu \mathrm{L}$ de agua destilada, $1765 \mu \mathrm{L}$ de pectina cítrica al 0,5\% (w/v) ( $>85 \%$ esterificación, Sigma ${ }^{\circledR}$ ), $445 \mu \mathrm{L}$ de azul de bromotimol al $0,01 \%$ en buffer fosfato de sodio al $0,006 \mathrm{M}$ y $495 \mu \mathrm{L}$ de extracto enzimático. Todos los reactivos se ajustaron a $\mathrm{pH} 7,5$ con hidróxido de sodio $(\mathrm{NaOH})$ $0,1 \mathrm{~N}$ y $1 \mathrm{~N}$.

El cambio de color se midió a una longitud de onda de $620 \mathrm{~nm}$. La pendiente de la parte lineal de la curva (velocidad inicial de la reacción) se tomó como actividad enzimática (Rudra Shalini et al., 2008). Los resultados se expresaron como el cambio en la densidad óptica por minuto ( $\Delta \mathrm{Abs} / \mathrm{min})$.

La actividad residual enzimática (AR), se define como la relación entre la actividad de la enzima después del tratamiento, a la actividad que tenía antes del mismo. Su cálculo se realiza utilizando la ecuación 1 , reportada por Tiwari et al., (2009) en términos de porcentaje.

$\% \mathrm{AR}=\frac{\mathrm{A}_{\mathrm{t}}}{\mathrm{A}_{0}} \times 100$

Donde: $A_{t}=$ Actividad enzimática del zumo tratado (pasteurizado) $\mathrm{A}_{0}=$ Actividad enzimática del zumo sin pasteurizar (testigo) 


\section{Diseño experimental}

Se planteó un diseño estadístico factorial multinivel con metodología de superficie de respuesta, evaluando dos factores, temperatura (entre $40^{\circ} \mathrm{C}$ y $60^{\circ} \mathrm{C}$ con 6 niveles) y tiempo de exposición (entre 5 y 20 segundos con 3 niveles), para un total de 18 corridas por bloque. Posteriormente se planteó un diseño de composición central con metodología de superficie de respuesta para encontrar el punto óptimo de inactivación enzimática. Este diseño contó con 10 corridas por bloque. La variable de respuesta fue el porcentaje de actividad residual. Todos los tratamientos se llevaron a cabo por cuadruplicado y siguiendo un orden aleatorio. El análisis de datos se realizó en el software estadístico InfoStat versión 2011 (Di Rienzo et al., 2010).

\section{Medición de la Concentración de Proteínas}

La concentración de proteína (enzima PME) se determinó mediante el método de Bradford, utilizando como estándar albúmina de suero bovino (BSA) a una longitud de onda de $595 \mathrm{~nm}$ (Bradford, 1976). La curva de calibración se realizó en un rango de proteína de $100-300 \mu \mathrm{g} / \mathrm{mL}$. Se tomaron $50 \mu \mathrm{L}$ de BSA o del extracto enzimático de tomate de árbol, (para la curva de calibración o la cuantificación de la enzima PME, respectivamente), se adicionó $1500 \mu \mathrm{L}$ del reactivo de Bradford [Thermo Scientific, 2010], y se incubó durante $10 \mathrm{~min}$ a temperatura ambiente; posteriormente se midió en el espectrofotómetro a $595 \mathrm{~nm}$ (Bollag et al., 1996).

\section{Preparación del néctar de tomate de árbol}

Para comprobar la efectividad de los tratamientos se preparó un néctar con la pulpa previamente pasteurizada, a la cual se agregó agua y azúcar y se envasó en botellas de vidrio estériles.

\section{Seguimiento del néctar pasteurizado}

Posterior a la pasteurización, el néctar se mantuvo en refrigeración $\left(4^{\circ} \mathrm{C}\right)$ durante 42 días con el fin de medir los cambios en la actividad enzimática y concentración de enzima en almacenamiento.

\section{RESULTADOS Y DISCUSIÓN}

Efecto de la aplicación de los tratamientos térmicos sobre la inactivación de PME

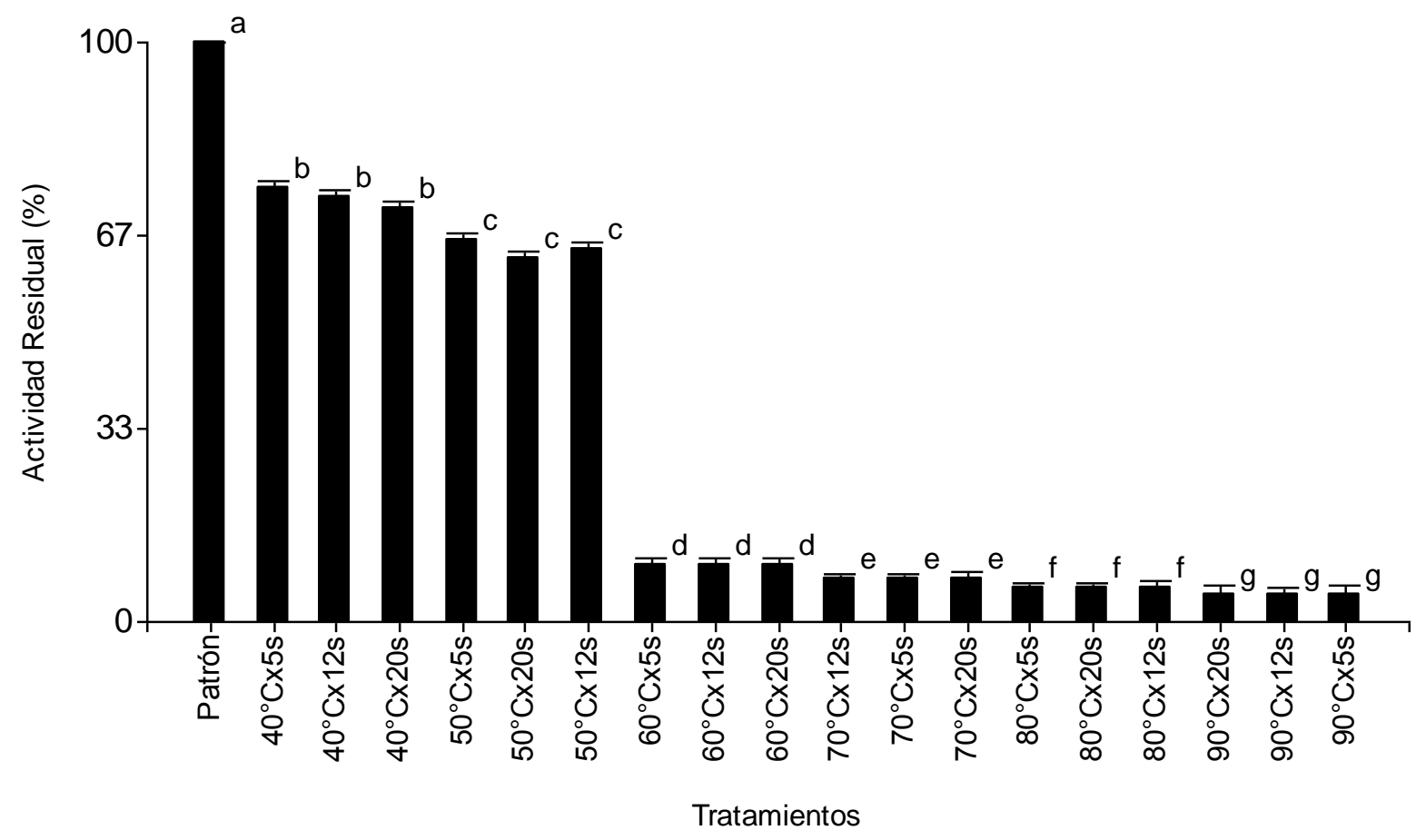

Fig.1: Porcentaje de actividad residual a diferentes tiempos y temperaturas

El efecto de los tratamientos sobre la actividad de la enzima se muestra en la Figura 1. Los tratamientos aplicados con temperaturas entre $40^{\circ} \mathrm{C}$ y $50^{\circ} \mathrm{C}$, provocaron una disminución de la AR hasta un $74 \%$ y $62 \%$, 
respectivamente, en todos los tiempos de retención. A temperaturas superiores $\left(60^{\circ} \mathrm{C}\right.$ a $\left.90^{\circ} \mathrm{C}\right)$, se nota un rápido descenso en la actividad residual, llegando a niveles entre el $9 \%$ y $4 \%$ respectivamente. La disminución de la actividad en la velocidad de reacción es probablemente el resultado de la desnaturalización de la enzima por el calor.

Dado que el objetivo fue encontrar el tratamiento óptimo que permitiera llevar la actividad residual hasta un $10 \%$ de su actividad inicial, se hicieron pruebas dentro de un nuevo rango de temperaturas que variaron entre $50^{\circ} \mathrm{C}$ y $60^{\circ} \mathrm{C}$. En la figura 2 se observa que la actividad residual disminuye a medida que los factores temperatura y tiempo se incrementan.

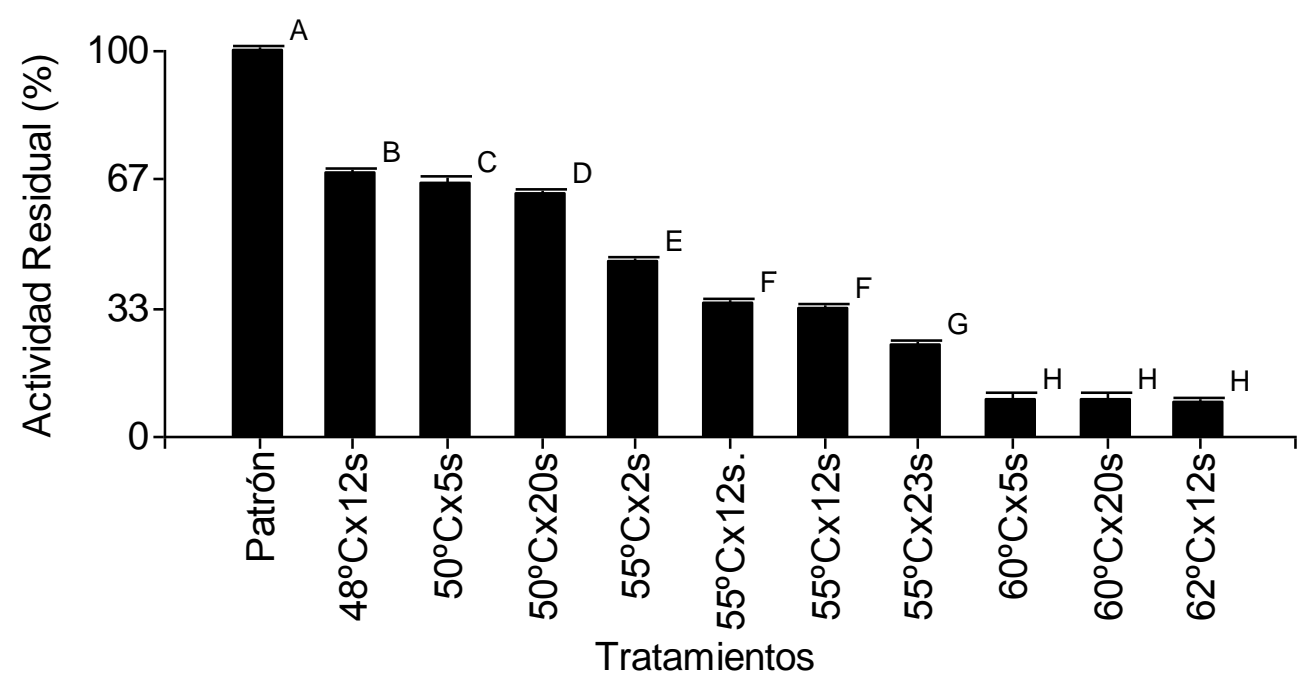

Medias con una letra común no son significativamente diferentes $(p<=0,05)$

Fig. 2: Porcentaje de actividad residual a Temperaturas entre $50^{\circ} \mathrm{C}$ y $60^{\circ} \mathrm{C}$

La gráfica de superficie de respuesta, obtenida mediante el diseño de composición central para las nuevas temperaturas, determinó que el tratamiento que cumplía la restricción planteada fue a una temperatura de $60^{\circ} \mathrm{C}$ durante $20 \mathrm{~s}$, como aparece en la figura 3. Esta combinación de factores logró mantener la actividad residual en un $10 \%$ y evitó la separación de fases, lo que no se logró con el mismo tratamiento durante un tiempo de retención de 5s.

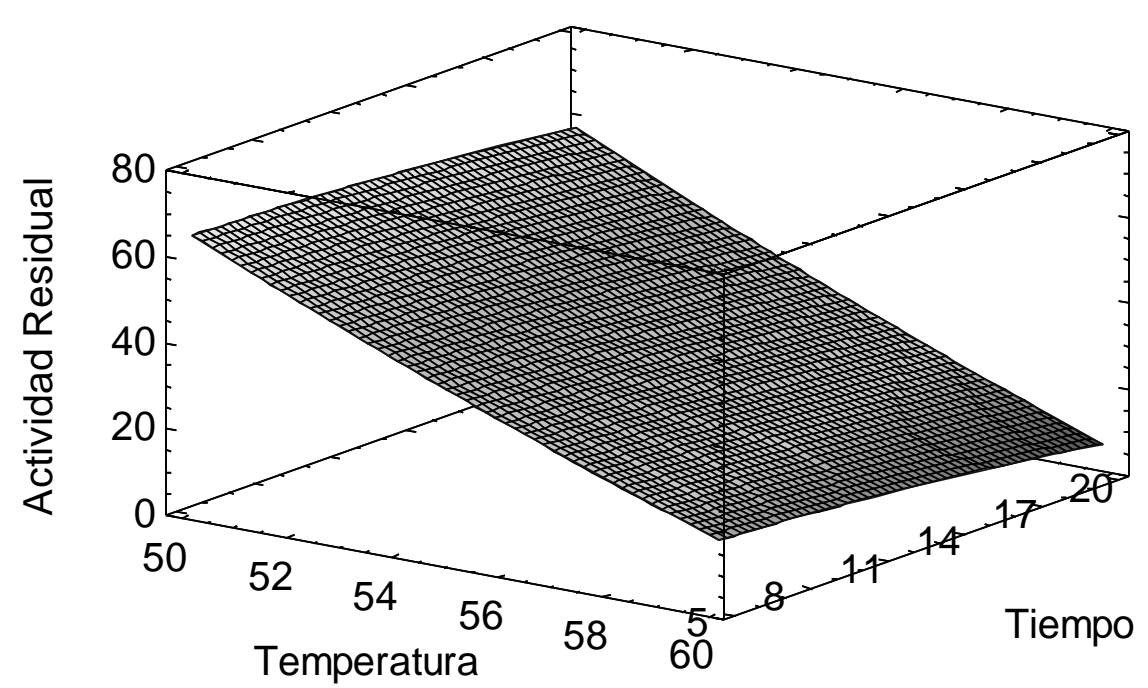

Fig. 3: Gráfica de Superficie de Respuesta Estimada para el rango de $50^{\circ} \mathrm{C}$ a $60^{\circ} \mathrm{C}$

El tratamiento térmico establecido se encuentra dentro de los rangos de otros reportados para la inactivación de PME en diferentes frutas. Stückrath et al. (1998), realizaron el análisis de termoestabilidad de PME extraída de frambuesas var. Meeker y concluyeron que al someter la enzima durante un minuto a distintas temperaturas en el rango de $40^{\circ} \mathrm{C}$ a $70^{\circ} \mathrm{C}$ la enzima es estable y de $70^{\circ} \mathrm{C}$ a $90^{\circ} \mathrm{C}$ es medianamente sensible, con un valor $z$ de $35,1^{\circ} \mathrm{C}$, lo que indica que en este producto la enzima es muy termoestable, a diferencia de otros productos. En PME extraída de guanábana, Arbaisah et al., (1997), obtuvieron una disminución de la actividad enzimática de un $80 \%$ luego de un tratamiento a $60^{\circ} \mathrm{C}$. 
Osorio et al., (2008), reportaron que una pasteurización suave $\left(75^{\circ} \mathrm{C}\right.$ por $\left.15 \mathrm{~s}\right)$ y una pasteurización severa $\left(90^{\circ} \mathrm{C}\right.$ por $\left.20 \mathrm{~s}\right)$ reducen la actividad de PME en purés de fresa en un $25,5 \%$ y $5,4 \%$ respectivamente. Carbonell et al., (2005) mencionan que los tratamientos de $70^{\circ} \mathrm{C}$ por 30 s ó $74^{\circ} \mathrm{C}$ por 10 s disminuyeron la actividad de PME en el zumo de mandarina por debajo del 10\%, mientras que en los zumos de híbridos fue necesario aplicar un tratamiento de $85^{\circ} \mathrm{C}$ por 10 s para lograr el mismo porcentaje de residualidad. Para el tratamiento térmico de jugos de naranjas y mandarinas Sentandreu et al., (2005) lograron una actividad residual de la enzima PME del $2 \%$ con un tratamiento de $85^{\circ} \mathrm{C}$ a $90^{\circ} \mathrm{C}$ durante 10 s.

Estos resultados difieren a aquellos obtenidos por Vivar-Vera et al., (2007), quienes obtuvieron un tratamiento de $80^{\circ} \mathrm{C}$ durante 10 minutos para inactivar completamente la enzima. Los autores explican que este resultado se debe a la alta afinidad que tiene la enzima por el sustrato utilizado ya que las pruebas se realizaron utilizando pectina extraída del fruto de tejocote en lugar de pectina cítrica.

Uno de los motivos de la discrepancia existente entre resultados es que la temperatura de inactivación de esta enzima muestra un amplio rango [Arbaisah et al., 1997], debido al gran número de isoenzimas reportadas. Seymour et al., (1991) estudiaron la termo estabilidad de PME en toronja var. Marsh y observaron que la fracción termolábil y termoestable se inactivaron completamente a $65^{\circ} \mathrm{C}$ y $85^{\circ} \mathrm{C}$, respectivamente. Versteeg et al., (1980) reportaron que las isoenzimas PME I, PME II y la PME de alto peso molecular de jugo de naranja fueron inactivadas rápidamente a $60^{\circ} \mathrm{C}, 70^{\circ} \mathrm{C}$ y $90^{\circ} \mathrm{C}$, respectivamente.

Estudios realizados en otros vegetales de la familia de las solanáceas también presentan resultados disímiles. Pressey y Avants, (1972) encontraron y aislaron cuatro isoenzimas de PME en el jugo de tomate de mesa, con distintas características y diferente termoestabilidad. Las isoenzimas A y B de PME extraída de tomate de mesa, fueron inactivadas mediante un calentamiento por 5 min a $63^{\circ} \mathrm{C}$ y $64^{\circ} \mathrm{C}$, donde se logró un $50 \%$ de inactivación, mientras que la temperatura de inactivación de la fracción C fue menor a $55^{\circ} \mathrm{C}$ (Warrilow, Turner, y Jones, 1994). Los ensayos de termo estabilidad de PME aislada de papa var Alpha, calentando durante 30 minutos, permitieron concluir que su actividad se incrementó sustancialmente hasta los $60^{\circ} \mathrm{C}$ y posteriormente decreció hasta un $30 \%$ a $70^{\circ} \mathrm{C}$ y hasta un $70 \%$ a $90^{\circ} \mathrm{C}$. Por lo tanto, la enzima se considera termo estable (Sáenz y Téllez, 2000).

Otra razón de las diferencias observadas en distintos productos es la diferencia en el pH del jugo de cada fruta. Para Anthon et al., (2002), esta diferencia es probablemente el resultado de la diferencia de $\mathrm{pH}$ en las soluciones de reacción utilizadas, ya que la tasa de inactivación es fuertemente dependiente del pH a valores entre 4 y 5 . Esto significa que entre más ácido sea el jugo más rápidamente se logrará la inactivación enzimática. Para el jugo de tomate de árbol, su pH varía entre 3,18 y 3,8 lo que podría explicar la rápida tasa de inactivación lograda en este estudio.

\section{Determinación de la Concentración de Proteínas}

Con la aplicación de tratamientos térmicos se logró una reducción del 30\% en la concentración de proteína a una temperatura de $62^{\circ} \mathrm{C}$ por $12 \mathrm{~s}$ y de un $28 \%$ con la aplicación del tratamiento óptimo encontrado $\left(60^{\circ} \mathrm{C}\right.$ por 20s).

La figura 4 muestra la concentración de proteína (enzima PME) presente en el zumo de tomate de árbol y su comportamiento bajo las diferentes condiciones de tiempo y temperatura. El análisis estadístico estableció que la concentración de proteína se ve afectada con el incremento de los factores tiempo y temperatura.

La actividad residual y la concentración de proteína poseen una relación directamente proporcional, pues de la cantidad de proteína activa (enzima activa) depende el porcentaje de actividad residual resultante. La desnaturalización de enzimas por calor, suele a menudo ser irreversible debido a la ruptura de enlaces covalentes y/o la agregación de proteínas desdobladas (Ly-Nguyen et al., 2003; Puppo et al., 2004).

Estudios realizados por Hirsch et al.,(2008) demuestran que la concentración de la enzima PME en jugo de naranja disminuye con el incremento de temperatura, pues la enzima se desnaturaliza, lo que a su vez mejora la retención de la turbidez del jugo. 


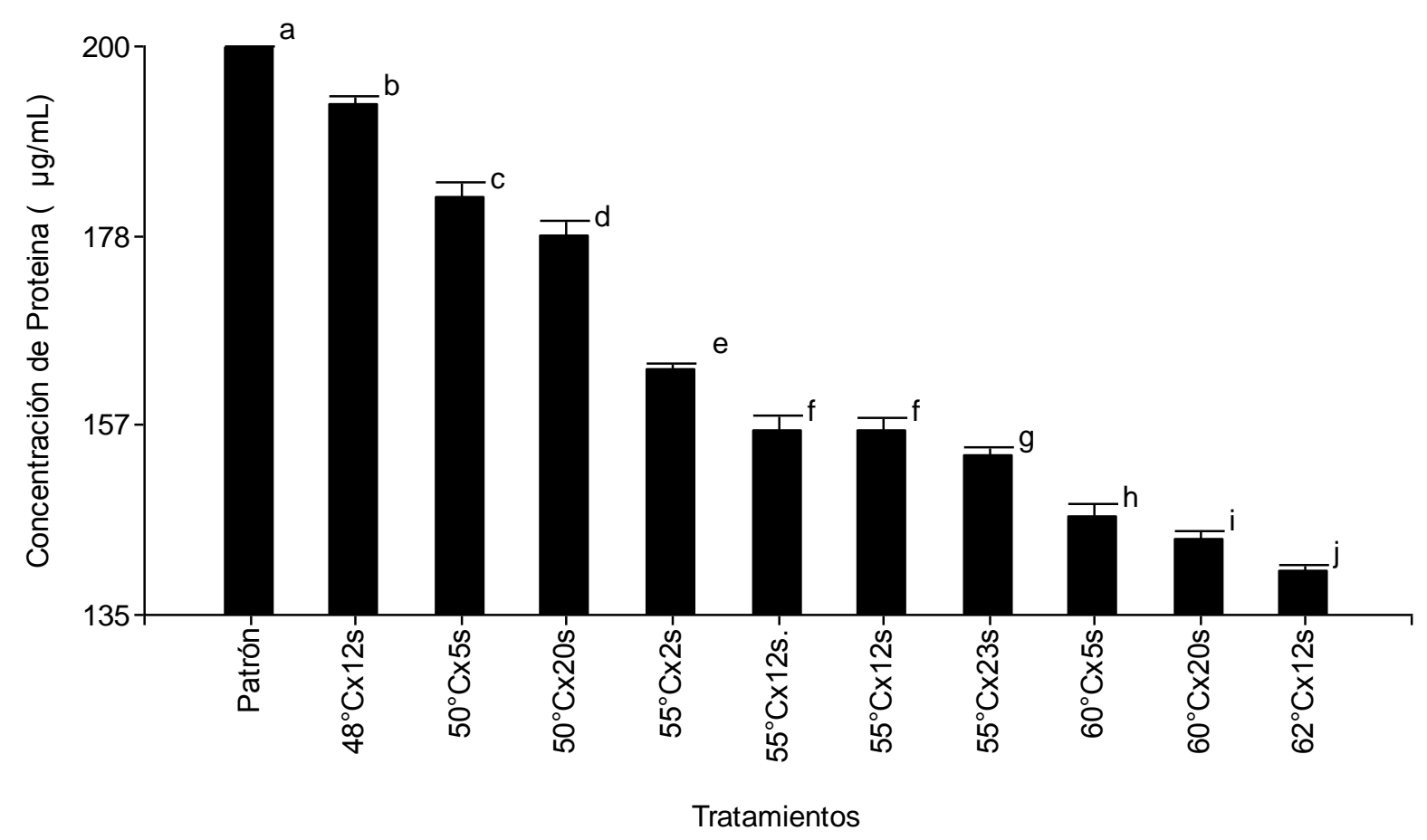

Fig.4: Cuantificación de proteína

En el caso de los jugos de cítricos, por ejemplo, estos contienen múltiples formas de PME, por lo cual es razonable esperar que la variación de las concentraciones de la enzima en jugos de distintas variedades requeriría diversos tiempos y temperaturas para su pasteurización térmica (Chen y Wu, 2007). De aquí se desprende el hecho de que no sea fácil comparar los resultados obtenidos con otros frutos similares.

\section{Seguimiento del néctar pasteurizado durante almacenamiento refrigerado}

Esta etapa se realizó con néctar preparado con pulpa previamente pasteurizada con el tratamiento óptimo $\left(60^{\circ} \mathrm{C}\right.$ por $\left.20 \mathrm{~s}\right)$. Los otros tratamientos no se consideraron en esta etapa del ensayo, puesto que los resultados de pruebas sensoriales llevadas a cabo por un panel de evaluación entrenado, dieron como resultado que los néctares preparados con pulpas tratadas a temperaturas superiores, producían un sabor a "cocido", que fue calificado como "desagradable" por los evaluadores (resultados no mostrados). Por ello se procedió a trabajar solo con el néctar preparado con el tratamiento óptimo. Los resultados de las evaluaciones para el seguimiento a la reactivación enzimática y la concentración de la enzima aparecen en la figura 5 y 6 , respectivamente.

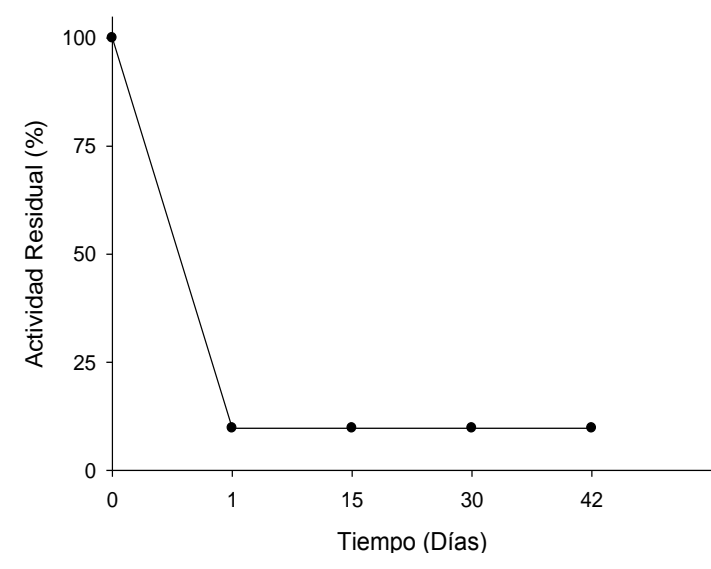

Fig.5: Actividad residual

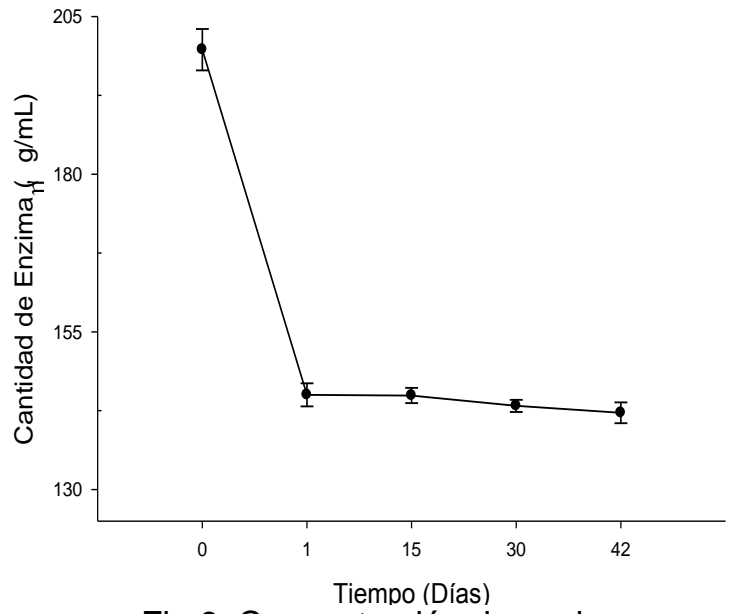

Fig.6: Concentración de enzima

Las figuras indican que el patrón difiere de la muestra tratada a $60^{\circ} \mathrm{C}$ por 20 s y evaluada a $1,15,30$ y 42 días, en donde a partir del día 1 posterior al tratamiento, la actividad residual y la cantidad de enzima permanecen constantes. El contenido de proteína de los jugos tratados disminuyó un $28-30 \%$ y se 
mantuvo durante el tiempo de almacenamiento, no observándose reactivación posterior. Estos resultados coinciden con los obtenidos por Hirsch et al., (2008) quienes observaron una disminución del $50 \%$ en el contenido de proteína de extractos de jugo de naranja pasteurizado durante su almacenamiento. Similares resultados reportan Ochoa y Guerrero (2012), quienes afirman que la baja actividad de la enzima PME durante el almacenamiento puede deberse a que esta no es muy eficiente en la degradación de la pectina en Tuna Roja.

Finalmente es importante resaltar que las condiciones de pasteurización para la inactivación de PME encontradas en esta investigación permiten conservar mayor cantidad de propiedades físicas, químicas y organolépticas del producto que los tratamientos térmicos severos. Según Osorio et al., (2008) el aumento de la intensidad de un tratamiento térmico destruye mayor cantidad de enzimas y microorganismos, pero también existe mayor alteración en el aroma, sabor y nutrientes del alimento.

\section{CONCLUSIONES}

El tratamiento de pasteurización aplicado $\left(60^{\circ} \mathrm{C}\right.$ por $\left.20 \mathrm{~s}\right)$ logra reducir la actividad enzimática hasta un $10 \%$, no reactivándose durante el periodo de tiempo estudiado y solucionando el problema de separación de fases generado por la enzima.

\section{AGRADECIMIENTOS}

A la Vicerrectoría de Investigaciones, Postgrados y Relaciones Internacionales VIPRI de la Universidad de Nariño, Colombia, por la financiación de esta investigación.

Al Grupo de Investigación Tecnologías Emergentes en Agroindustria TEA - Facultad de Ingeniería Agroindustrial, Universidad de Nariño.

Al Ingeniero Francisco José Muñoz O., IAI, MSc., por su asesoría en el diseño estadístico.

\section{REFERENCIAS}

Anthon, G. E., y D. M. Barrett, Kinetic parameters for the thermal inactivation of quality-related enzymes in carrots and potatoes, Journal of Agricultural and Food Chemistry, 50(14), 4119-4125 (2002).

Anthon, G. E., Y. Sekine, N. Watanabe, y D. M. Barrett, Thermal inactivation of pectin methylesterase, polygalacturonase, and peroxidase in tomato juice, Journal of Agricultural and Food Chemistry, 50(21), 6153-6159 (2002).

Arbaisah, S. M., B. A. Asbi, A. H. Junainah, B. Jamilah, y J. F. Kennedy, Soursop pectinesterases: thermostability and effect on cloud stability of soursop juice, Carbohydrate Polymers, 34(3), 177-182 (1997).

De Assis, S., D. Lima, y O. de F. Oliveira, Activity of pectinmethylesterase, pectin content and vitamin $C$ in acerola fruit at various stages of fruit development, Food Chemistry, 74, 2-6 (2001).

Bollag, D. M., M. D. Rozycki, y S. J. Edelstein, Protein methods, 2nd ed., Wiley, New York, NY (1996).

Bradford, M. M., A rapid and sensitive method for the quantitation of microgram quantities of protein utilizing the principle of protein-dye binding, Analytical Biochemistry, 72, 248-54 (1976).

Carbonell, J. V., P. Contreras, L. Carbonell, y J. L. Navarro, Pectin methylesterase activity in juices from mandarins, oranges and hybrids, European Food Research and Technology, 222(1-2), 83-87(2005).

Chen, C., y M. Wu, Kinetic models for thermal inactivation of multiple pectinesterases in citrus juices, Journal of Food Science, 63(5), 1-4 (2007).

Cruz, R. M. S., M. C. Vieira, y C. L. M. Silva, Effect of heat and thermosonication treatments on peroxidase inactivation kinetics in watercress (Nasturtium officinale), Journal of Food Engineering, 72(1), 8-15 (2006).

Fellows, P., Tecnologia del procesado de los alimentos: Principios y practicas, Editorial Acribia S.A., Zaragoza, España (1994). 
Giner, J., V. Gimeno, y A. Espachs, Inhibition of tomato ( Licopersicon esculentum Mill.) pectin methylesterase by pulsed electric fields, Innovative Food Science \& Emerging Technologies, 1(1) 57-67 (2000).

Hagerman, A. E., y Austin, P. J., Continuous spectrophotometric assay for plant pectin methyl esterase. Journal of Agricultural and Food Chemistry,34(3), 440-444 (1986).

Hirsch, A. R., K. Förch, S. Neidhart, G. Wolf, y R. Carle, Effects of thermal treatments and storage on pectin methylesterase and peroxidase activity in freshly squeezed orange juice, Journal of Agricultural and Food Chemistry, 56(14), 5691-5699 (2008).

ICONTEC Instituto Colombiano de Normas Técnicas y Certificación, Norma Técnica Colombiana (NTC4105), Bogotá, D.C (1997).

Ingallinera, B., R. N. Barbagallo, G. Spagna, R. Palmeri, y A. Todaro, Effects of thermal treatments on pectinesterase activity determined in blood oranges juices, Enzyme and Microbial Technology, 36(2-3), 258263 (2005).

Jakób, A., J. Bryjak, y M. Polakovič, Selection of a method for determination of activity of pectinolytic enzymes in berry fruit materials, Chemical Papers, 63(6), 677-682 (2009).

Jolie, R. P., y seis autores más, Carrot pectin methylesterase and its inhibitor from kiwi fruit: Study of activity, stability and inhibition, Innovative Food Science \& Emerging Technologies, 10(4), 601-609 (2009).

Lewis, M. J., y N. Heppell, Continuous Thermal Processing of Foods : Pasteurization and UTH Sterilization, Aspen, Gaithersburg, EUA (2000).

Luíz, R. C., T. A. M. Hirata, y E. Clemente, Cinética de inativação da polifenoloxidase e peroxidase de abacate (Persea americana MILL.), Ciência e Agrotecnologia, 31(6), 1766-1773 (2007).

Ly-Nguyen, y ocho autores más, Mild-Heat and High-Pressure Inactivation of Carrot Pectin Methylesterase: A Kinetic Study, Journal of Food Science, 68(4), 1377-1383 (2003).

Menéndez- Aguirre, O., y cinco autores más, Cambios en la actividad de a-amilasa, pectinmetilesterasa y poligalacturonasa durante la maduración del Maracuyá Amarillo (Passiflora edulis var. Flavicarpa Degener), Interciencia, 31(10), 728-733 (2006).

Ochoa, C. E., y J. A. Guerrero, Efecto del Almacenamiento a Diferentes Temperaturas sobre la Calidad de Tuna Roja (Opuntia ficus indica (L.) Miller), Información tecnológica, 23(1), 117-128 (2012).

Osorio, O., N. Martinez-Navarrete, G. Moraga y J. V. Carbonell, Effect of Thermal Treatment on Enzymatic Activity and Rheological and Sensory Properties of Strawberry Purees, Food Science and Technology International, 14(5 suppl), 103-108 (2008).

Polydera, A. C., E. Galanou, N. G. Stoforos, y P. S. Taoukis, Inactivation kinetics of pectin methylesterase of greek Navel orange juice as a function of high hydrostatic pressure and temperature process conditions, Journal of Food Engineering, 62(3), 291-298 (2004).

Pressey, R., y J. K. Avants, Multiple forms of pectinesterase in tomatoes, Phytochemistry, 11(11), 3139$3142(1972)$.

Puppo, C., y seis autores más, Physicochemical modifications of high-pressure-treated soybean protein isolates, Journal of Agricultural and Food Chemistry, 52(6), 1564-1571(2004).

Di Rienzo, y cinco autores más, InfoStat versión 2010, Grupo InfoStat FCA Universidad Nacional de Córdoba Argentina (2010). 
Rivas, A., D. Rodrigo, A. Martínez, G. V. Barbosa-Cánovas, y M. Rodrigo, Effect of PEF and heat pasteurization on the physical-chemical characteristics of blended orange and carrot juice, LWT - Food Science and Technology, 39(10), 1163-1170 (2006).

Rudra Shalini, G., U. S. Shivhare, y S. Basu, Thermal inactivation kinetics of peroxidase in mint leaves, Journal of Food Engineering, 85(1), 147-153 (2008).

Sentandreu, E., L. Carbonell, J. V. Carbonell, y L. Izquierdo, Effects of Heat Treatment Conditions on Fresh Taste and on Pectinmethylesterase Activity of Chilled Mandarin and Orange Juices, Food Science and Technology International, 11(3), 217-222 (2005).

Seymour, T. A., J. F. Preston, L. Wicker, J. A. Lindsay, y M. R. Marshall, Purification and properties of pectinesterases of Marsh white grapefruit pulp, Journal of Agricultural and Food Chemistry, 39(6), 10801085 (1991).

Stückrath, R., D. Díaz, y L. Trujillo, Purificación y caracterización de Pectinesterasa extraída de frambuesas de la variedad Meeker, Información Tecnológica, 9(5), 45-48 (1998).

Sáenz, J., and A. Téllez, Purification and some properties of pectinesterase from potato (Solanum tuberosum L.) Alpha cultivar, Brazilian Archives of Biology and Technology, 43(4) (2000).

Thermo Scientific, Instructions Coomassie Plus (Bradford) Assay Kit (23236), en línea, http://www.piercenet.com/instructions/2160229.pdf. Acceso: 12 de abril (2010)

Thongsook, T., y D. M. Barrett, Purification and partial characterization of broccoli (Brassica oleracea Var. Italica) peroxidases, Journal of Agricultural and Food Chemistry, 53(8), 3206-14 (2005).

Tiwari, B. K., K. Muthukumarappan, C. P. O'Donnell, y P. J. Cullen, Inactivation kinetics of pectin methylesterase and cloud retention in sonicated orange juice, Innovative Food Science \& Emerging Technologies, 10(2), 166-171 (2009).

Torres, E. F., S. Bayarri, F. Sampedro, A. Martinez, y J. V. Carbonell, Improvement of the Fresh Taste Intensity of Processed Clementine Juice by Separate Pasteurization of its Serum and Pulp, Food Science and Technology International, 14(6), 525-529 (2008).

Versteeg, C., F. M. Rombouts, C. H. Spaansen, y W. Pilnik, Thermostability And Orange Juice Cloud Destabilizing Properties Of Multiple Pectinesterases From Orange, Journal of Food Science, 45(4), 969-971 (1980).

Vicente, A. R., Efectos de tratamientos térmicos de alta temperatura sobre calidad y fisiología postcosecha de frutillas (Fragaria $x$ ananassa Duch), Universidad Nacional de la Plata, Agentina (2004).

Vivar-Vera, M. A., J. A. Salazar-Montoya, G. Calva-Calva, y E. G. Ramos-Ramírez, Extraction, thermal stability and kinetic behavior of pectinmethylesterase from hawthorn (Crataegus pubescens) fruit, LWT Food Science and Technology, 40(2), 278-284 (2007).

Warrilow, A. G. S., R. J. Turner, y M. G. Jones, A novel form of pectinesterase in tomato, Phytochemistry, 35(4), 863-868 (1994). 